\title{
Increase of cases of legionellosis in Latvia, 2011
}

B Rozentale ${ }^{1}$, A Bormane $^{1}$, J Perevoščikovs (jurijs.perevoscikovs@lic.gov.lv) ${ }^{1}$, I Lucenko ${ }^{1}$, A Brila $^{1}$

1. State Agency "Infectology Center of Latvia", Latvia

Citation style for this article:

Rozentale B, Bormane A, Perevoščikovs J, Lucenko I, Brila A. Increase of cases of legionellosis in Latvia, 2011.

Euro Surveill. 2011;16(45):pii=20009. Available online: http://www.eurosurveillance.org/ViewArticle. aspx?Articleld=20009

Article published on 10 November 2011

An increased number of legionellosis cases in 2011 has been reported in Latvia, compared to the ten previous years. A total of 30 legionellosis cases (1.35 per 100,000 inhabitants), including 19 females, have been confirmed until the end of September 2011. The majority of cases $(n=23)$ were inhabitants of the capital city Riga. The reason for the increase in legionellosis is unclear. Twenty-six of the 30 cases are not travel-related.

In 2011, increased numbers of legionellosis case notifications have been noted in Latvia, compared with previous years. From 2001 to 2010, a total of 22 cases were notified to the State Agency "Infectology Center of Latvia” (LIC). In 2011, there were at least two cases per month from March onwards, contributing to a total of 26 autochthonous cases until September 2011.

Legionellosis or Legionnaires' disease is a mild to severe pneumonia caused by bacteria of the genus Legionella. Legionella bacteria are found in environmental fresh waters, and have a potential to proliferate in great quantities in badly maintained human-made water systems, such as spas, baths, cooling towers, hot and cold water systems. Legionellosis can occur when Legionella-contaminated water aerosols created by for example showers and taps are inhaled [1-3]. In most cases, legionellosis is caused by the Legionella pneumophila serogroup 1 [4-6].

\section{Notification of legionellosis in Latvia}

In Latvia, legionellosis was included in the list of mandatorily notifiable diseases in 1999. Healthcare practitioners are legally responsible for notifying infectious diseases and each legionellosis case or professionally well-founded suspicion of legionellosis have to be notified to the regional epidemiologists within 24 hours by phone, and by sending a special urgent notification form. Notification is required for suspected Legionella cases and then additional notifications are required if a diagnosis is changed or discarded, as well as for the final diagnosis and outcome of disease and laboratory confirmation of the diagnosis. Since 2009, cases of legionellosis have to be notified by microbiological laboratories as well. The case classification as probable or confirmed is based on the European Union (EU) case definition [7].

Regional epidemiologists of the LIC State Agency after receipt of the information from healthcare practitioners or laboratories collect, store and analyse the epidemiological data. They can also perform an investigation of the cases, and take environmental samples for laboratory testing, including water from suspected Legionella-contaminated water systems. The LIC is also responsible for organising and advising on preventive and control measures.

\section{Legionellosis in Latvia from 2001 to 2011}

The first autochtonous legionellosis cases in Latvia were registered in 2001 and 2002. Subsequently no cases were reported during the three following years. The average number of cases per year in the period from 2001 to 2009 was 2.2 (range: 1-5), which corresponds to a mean incidence of 0.09 per 100,000 inhabitants (Figure 1).

The number of cases reached six (0.27 per 100,000 inhabitants) in 2010. Among cases, two were likely to have been infected abroad, while for the rest, the source of infection remains unconfirmed. None of the water samples taken at the patients' dwellings revealed Legionella prevalence.

\section{FIGURE 1}

Legionellosis incidence rate in Latvia, 1 January 2001-30 September $2011(n=52)$

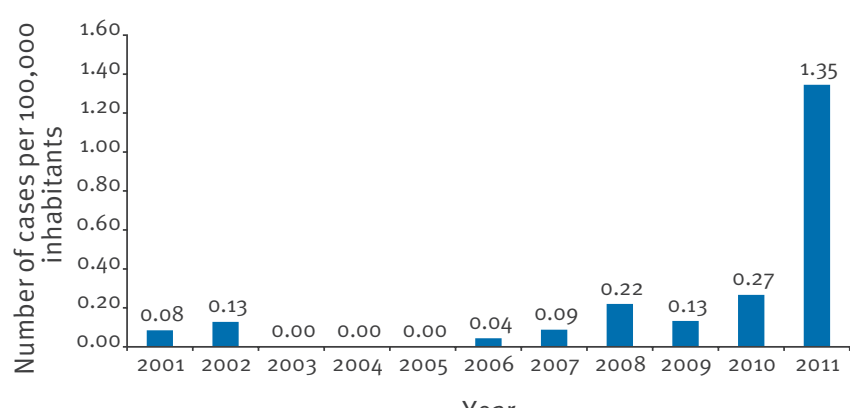

Year 


\section{Epidemiological situation in 2011}

In 2011, a total of 30 legionellosis cases (1.35 per 100,000 inhabitants) were registered until the end of September (Figure 2) and an epidemiological investigation of all cases was performed. Of the 30 registered cases, 17 were confirmed serologically by demonstration of a specific antibody response to Legionella pneumophila by single high titre, while 11 were confirmed by detection of specific Legionella antigen in urine, and two were confirmed by both of the mentioned methods.

Of the legionellosis cases, 17 were treated in the only specially designated hospital for infectious diseases in the country, which is at the LIC in Riga. The rest were admitted to six other different hospitals/rehabilitation centres. Two of the cases in the age group 45-55 years were fatal and consisted of a woman and a man, who was a heavy smoker. Neither fatal case had any documented underlying diseases.

A standard questionnaire was used during the epidemiological investigation in order to interview patients with legionellosis. The questionnaire included travel history and other possible risk factors/exposures. There were only four cases likely to have been infected abroad in 2011, either in Germany, Czech Republic, India or Mexico, where they had travelled/worked during their incubation period (two of them mentioned that they could have been infected during a stay in a hotel). The 26 remaining patients reported no travel abroad. Among them, 23 were inhabitants of the capital city Riga, with their residences scattered at either side of the Daugava river which divides the city (Figure 3). The other three were from other cities in the western and central part of the country.

In 2011, 19 legionellosis patients were females while only 11 were male. For female patients, the highest incidence occurred in the 18-29 and older than 60 year age groups, while most male patients were between 40 and 59 years old (Figure 4 ).

\section{FIGURE 2}

Legionellosis cases by month of registration, Latvia, 2011 $(\mathrm{n}=30)$

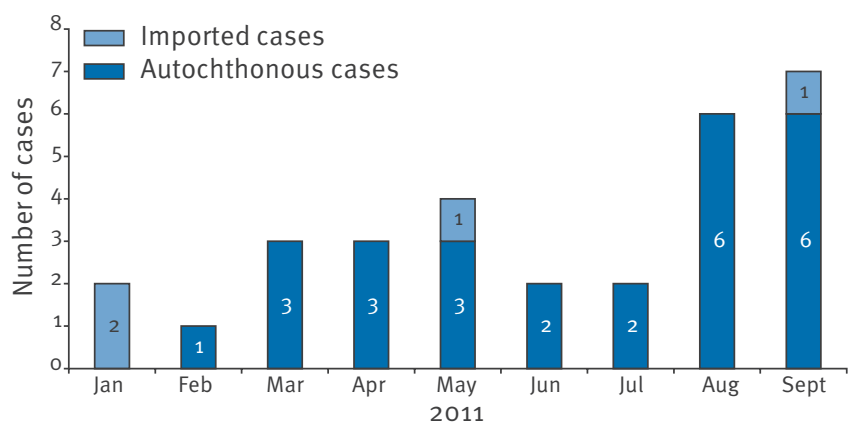

\section{Environmental investigation}

During the epidemiological investigation of cases, a total of 52 households were visited and 114 water samples were collected and tested for the prevalence of Legionella spp. (Table 1).

For 12 legionellosis cases, Legionella spp. were found in the water-supply system of the patients' households, including the heating units of the apartment house. In the majority of samples, bacteria were found in the hot water ( $55 \%$ in the house heating units, and $24 \%$ in the

\section{FIGURE 3}

Distribution of cases of legionellosis in Riga, Latvia, 1 January-30 September $2011(n=23)$

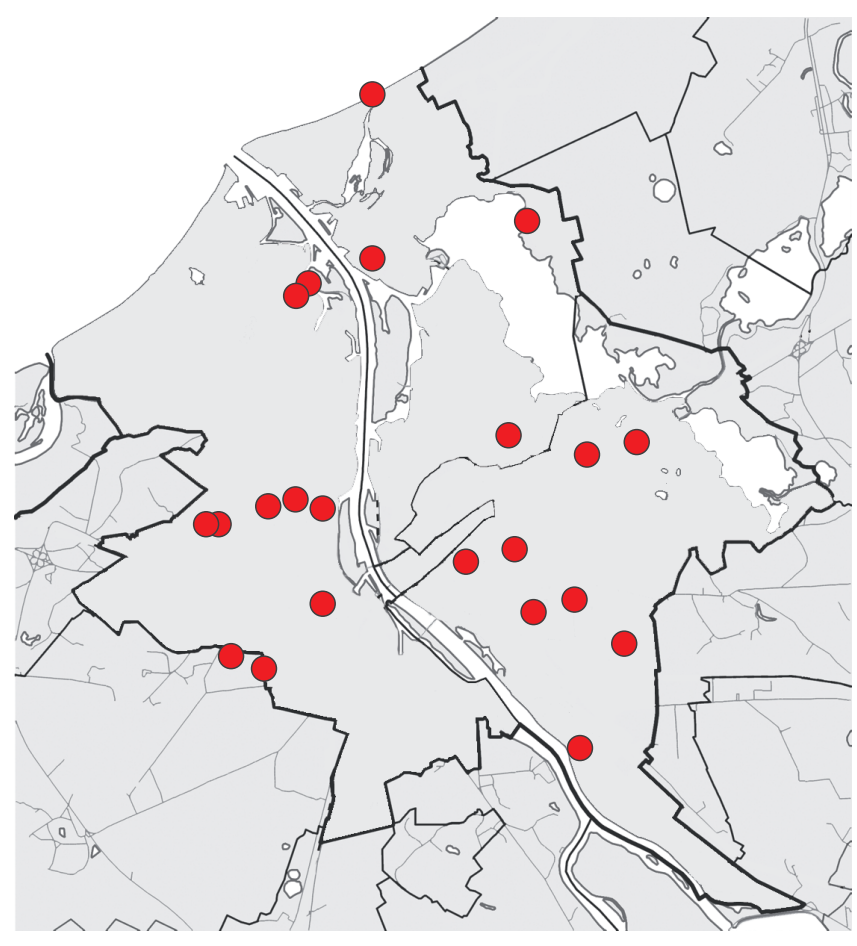

Only 22 locations are indicated on the map for the 23 cases, because two cases occurred from the same location.

\section{FIGURE 4}

Legionellosis incidence rate by age group and sex, Latvia, $2011(n=30)$

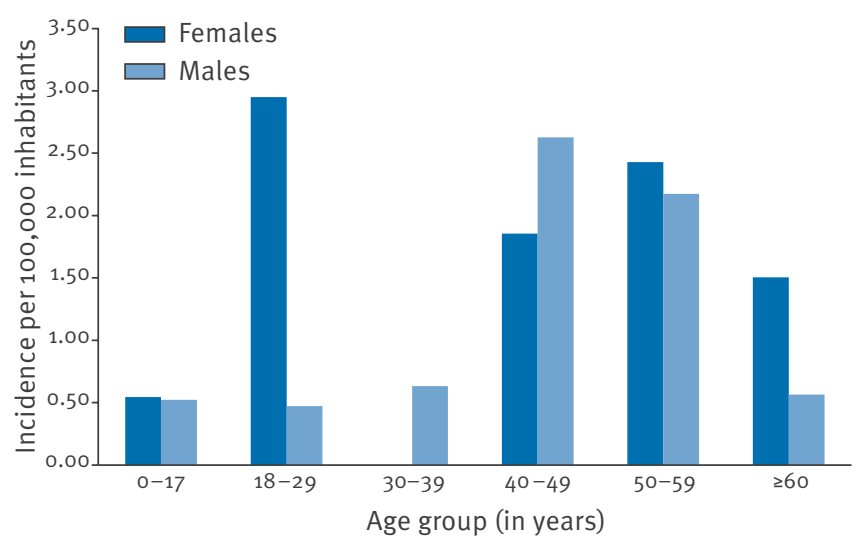


flats), while in cold water samples - only $15 \%$ and $8 \%$ accordingly. Legionella pneumophila serogroup 1 was found in seven of 26 positive samples $(27 \pm 8.87 \%)$, while other serogroups (2-14) were found in 19 samples (73ะ8.87\%).

\section{Control measures}

As soon as an increase of legionellosis cases in Latvia was detected, the LIC prepared and provided information for practitioners and clinicians of all hospitals, including case definitions and diagnostic methods. As a response to the emerging situation, a notable information campaign was undertaken, to involve and educate institutions responsible for water system maintenance, such as city councils, house management offices, city heating suppliers, city water suppliers, as well other competent bodies such as the Ministry of Health, Health Inspection, Association of the Family doctors, hospitals and society via mass media.

\section{Discussion}

The reasons for the increased legionellosis case numbers in Latvia in 2011 are unclear. Apart from the four cases who travelled abroad, no common risk factor or exposure could be identified. There were, moreover, no changes in the availability of diagnostic tests in Riga, compared with previous years, which could have accounted for differences in the number of confirmed cases in 2011. Among possible factors that could have contributed to the increase, the enhanced awareness of healthcare practitioners could have played a role, as it would have resulted in a reduction of underdiagnosed cases of pneumonia. It has been reported that the main reason for not diagnosing legionellosis in patients is a lack of clinical awareness [5]. Another explanation for the increase of legionellosis cases could be the unfavourable economical situation, which compels the population to spare water and energy. In this case, inhabitants request heating regulators to decrease the temperature of hot water systems leading an increased contamination of these systems. Legionella can multiply between $25^{\circ} \mathrm{C}$ and $42^{\circ} \mathrm{C}$, and the optimal proliferation temperature of the bacteria is $35^{\circ} \mathrm{C}[5]$. Also, it cannot be excluded that two exceptionally hot summers in 2011 influenced the drinking water contamination load with Legionella.

In our study, the male/female ratio of cases was also inverse to the usual trend, where males dominate $[6,8]$.
This could be due to chance and the small numbers did not really allow reliable statistical analysis, but could be also partially explained by the male/female ratio in the Latvian population which is $0.86(1,029,391$ males $/ 1,200,250$ females) [9]. Some unstated activities at households, more specific to women could influence the situation as well. .

References

1. Krøjgaard LH, Krogfelt KA, Albrechtsen $\mathrm{HJ}$, Uldum SA. Cluster of Legionnaires disease in a newly built block of flats, Denmark, December 2008 - January 2009. Euro Surveill. 2011;16(1) : pii=19759. Available from: http://www. eurosurveillance.org/ViewArticle.aspx?Articleld=19759

2. Campese $C$, Roche $D$, Clément $C$, Fierobe $F$, Jarraud $S$, de Waelle $P$, et al. Cluster of Legionnaires' disease associated with a public whirlpool spa, France, April - May 2010. Euro Surveill. 2010;15(26):pii=19602. Available from: http://www. eurosurveillance.org/ViewArticle.aspx?Articleld=19602

3. European Surveillance Scheme for Travel Associated Legionnaires' Disease (EWGLINET), European Working Group for Legionella Infections (EWGLI). European Guidelines for Control and Prevention of Travel Associated Legionnaires' Disease. London: Health Protection Agency (HPA); Jan 2005. Available from: http://www.hpa.org.uk/webc/HPAwebFile/ HPAweb_C/1274093149925

4. Keramarou M, Evans MR, for the South Wales Legionnaires' Disease Outbreak Control Team. A community outbreak of Legionnaires' disease in South Wales, August-September 2010. Euro Surveill. 2010;15(42):pii=19691. Available from: http://www.eurosurveillance.org/ViewArticle. aspx?Articleld $=19691$

5. Fields BS, Benson RF, Besser RE. Legionella and Legionnaires' Disease: 25 years of investigation. Clin. Microbiol. Rev. 2002;15(3):506-26.

6. Campese C, Bitar D, Jarraud S, Maine C, Forey F, Etienne J, et al. Progress in the surveillance and control of Legionella infection in France, 1998-2008. Int J Infect Dis. 2011;15(1):e30-7

7. European Commission Decision 2008/426/EC of 28 April 2008 amending Decision 2002/253/EC laying down case definitions for reporting communicable diseases to the Community network under Decision No 2119/98/EC of the European Parliament and of the Council (notified under document number C(2008) 1589) (Text with EEA relevance). Available from: http://eur-lex.europa.eu/Result.do? $\mathrm{T}_{1}=\mathrm{V}_{4} \& \mathrm{~T}_{2}=2008 \& \mathrm{~T}_{3}=$ 426\&RechType $=$ RECH_naturel $\&$ Submit $=$ Search

8. Joseph CA, Ricketts KD, Yadav R, Patel S, on behalf of the European Working Group for Legionella Infections. Travelassociated Legionnaires' disease in Europe in 2009. Euro Surveill. 2010;15(41):pii=19683. Available from: http://www. eurosurveillance.org/ViewArticle.aspx?Articleld $=19683$

9. Data of Central Statistical Bureau of Latvia (http://www.csb. gov.lv/en/dati/key-indicators-30780.html

\section{TABLE 1}

Investigation of environmental samples for Legionella spp. prevalence, Latvia, 1 January-30 September 2011 (n=114)

\begin{tabular}{|l|c|c|c|}
\hline Sample collection site & Sample type & Number of samples tested & $\begin{array}{c}\text { Legionella positive } \\
\mathrm{n}(\% \pm \text { Standard deviation) }\end{array}$ \\
\hline \multirow{2}{*}{$\begin{array}{l}\text { Apartment house } \\
\text { (heating units) }\end{array}$} & Hot water & 20 & $11(55 \pm 11)$ \\
\hline \multirow{2}{*}{\begin{tabular}{l} 
Flats (taps or showers) \\
\cline { 2 - 4 }
\end{tabular}} & Cold water & 13 & $2(15 \pm 10)$ \\
\cline { 2 - 4 } & Hot water & 42 & $10(23 \pm 7)$ \\
\hline
\end{tabular}

